\title{
Effect of oral propranolol on rest and exercise left ventricular ejection fraction, volumes, and segmental wall motion in patients with angina pectoris Assessment with equilibrium gated blood pool imaging*
}

\author{
GREGORY J DEHMER, MICHAEL FALKOFF, SAMUEL E LEWIS, \\ L DAVID HILLIS, ROBERT W PARKEY, JAMES T WILLERSON
}

From the Departments of Internal Medicine (Cardiology Division) and Radiology (Nuclear Medicine) at the University of Texas Health Science Center and Parkland Memorial Hospital in Dallas, Texas, USA

SUMMARY The effect of oral propranolol on left ventricular ejection fraction, left ventricular volumes, cardiac output, and segmental wall motion was assessed with multigated blood pool imaging both at rest and during supine exercise in 15 patients with angina pectoris. Propranolol had no effect on resting left ventricular ejection fractions. Before propranolol, they did not change during exercise, whereas after propranolol the ejection fractions increased slightly. Exercise left ventricular ejection fractions increased with propranolol in three patients with resting left ventricular ejection fractions of $<40$ per cent.

More specifically, left ventricular end-diastolic volume index, end-systolic volume index, stroke volume index, and cardiac index were not altered significantly at rest or during exercise by propranolol. Exercise left ventricular ejection fractions were increased in five and unchanged in eight patients by propranolol. Those patients with increases in left ventricular ejection fractions had a greater change in left ventricular end-diastolic volume indices and a greater change in left ventricular end-systolic volume indices during exercise while on propranolol. Left ventricular segmental wall motion was not altered significantly during exercise by propranolol.

We conclude that: (1) Left ventricular functional responses to propranolol during exercise are heterogeneous and not easily predicted; (2) propranolol causes no consistent deterioration in exercise left ventricular ejection fraction even in patients with resting left ventricular ejection fractions $<40$ per cent; (3) increased exercise left ventricular ejection fraction with propranolol is contributed to by significant increases in end-diastolic volume during exercise; and (4) gated blood pool imaging is a useful method for characterising rest and exercise left ventricular ejection fractions and left ventricular volumes during propranolol therapy.

The beneficial effects of propranolol on exerciseinduced myocardial ischaemia are well known. ${ }^{1}$ The administration of propranolol inhibits the positive inotropic and chronotropic responses to local and circulating catecholamines, often resulting in less frequent angina pectoris and improved exercise tolerance. In some patients, however, left ventricular function may deteriorate with propranolol treatment resulting in congestive heart failure. Previous studies using the acute administration of intravenous propranolol in man

*This work was supported by an NIH Ischaemic SCOR grant and the Harry $S$ Moss Heart Fund.

Received for publication 6 November 1980 have failed to document a consistent negative effect on left ventricular function in the basal state. $^{2-5}$ In addition, the effects of oral propranolol on myocardial function at rest have not been characterised completely. ${ }^{6-8}$ Since the effects of propranolol should be most pronounced during periods of sympathetic stimulation (such as exercise), and since the chronic oral effects of propranolol may be different from those produced by single dose intravenous treatment it seems important to evaluate the influence of chronic oral propranolol treatment on left ventricular function both at rest and during exercise. Several preliminary reports and one recent detailed communication have sug. 
gested that oral propranolol improves left ventricular ejection fraction during exercise in patients with coronary artery disease.$^{8-10}$ The present study was performed to assess the effects of oral propranolol on resting and exercising left ventricular performance in individuals with angina pectoris, using the technique of multigated equilibrium blood pool imaging. We specifically wished to determine whether: (1) chronic oral propranolol treatment increases left ventricular ejection fraction during exercise; (2) propranolol administration has any consistent beneficial or detrimental effect on left ventricular volumes that might not be apparent if only left ventricular ejection fraction is analysed; and (3) whether there are identifiable patient subgroups that have different left ventricular functional responses to propranolol during exercise.

\section{Patients and methods}

\section{PATIENT POPULATION}

The study population consisted of 15 patients with angina pectoris (13 male and 2 female) with a mean age of 56.4 years (range, 39 to 73 years) (Table 1). In all patients propranolol treatment was instituted for the treatment of angina pectoris.

Table 1 Patient data

\begin{tabular}{|c|c|c|c|c|c|}
\hline \multirow{2}{*}{$\begin{array}{l}\text { Case } \\
\text { No. }\end{array}$} & \multirow{2}{*}{$\begin{array}{l}\text { Age } \\
(y)\end{array}$} & \multirow[t]{2}{*}{ Sex } & \multirow{2}{*}{$\begin{array}{l}\text { Maximum } \\
\text { propranolol } \\
\text { dose/day }(\mathrm{mg})\end{array}$} & \multicolumn{2}{|c|}{ Peak workload (kpm) } \\
\hline & & & & Baseline & Propranolol \\
\hline 1 & 73 & $\mathbf{M}$ & 400 & 150 & 300 \\
\hline 2 & 66 & $\mathbf{F}$ & 160 & 300 & 300 \\
\hline 3 & 40 & $\mathbf{M}$ & 160 & 450 & 600 \\
\hline 4 & 61 & $\mathbf{M}$ & 80 & 450 & 300 \\
\hline 5 & 65 & $\mathbf{M}$ & 80 & 450 & 450 \\
\hline 6 & 39 & $\mathbf{M}$ & 60 & 150 & 150 \\
\hline 7 & 53 & $\mathbf{M}$ & 320 & 300 & 600 \\
\hline 8 & 57 & $\mathbf{M}$ & 120 & 150 & 150 \\
\hline 9 & 62 & $\mathbf{M}$ & 80 & 150 & 300 \\
\hline 10 & 61 & $\mathbf{M}$ & 320 & 150 & 150 \\
\hline 11 & 64 & $M$ & 80 & 150 & 150 \\
\hline 12 & 68 & $\mathbf{M}$ & 160 & 150 & 150 \\
\hline 13 & 40 & $\mathbf{M}$ & 160 & 600 & 600 \\
\hline 14 & 53 & $\mathbf{M}$ & 80 & 150 & 150 \\
\hline 15 & 44 & $\mathrm{~F}$ & 160 & 300 & 300 \\
\hline
\end{tabular}

The diagnosis of coronary artery disease was based on a history of angina pectoris and: (1) the angiographic demonstration of coronary artery narrowing equal to or greater than a 70 per cent decrease in luminal diameter (10 patients), and/or (2) an abnormal exercise tolerance test demonstrating $1 \mathrm{~mm}$ or greater horizontal or downsloping ST segment depression of a least $0.08 \mathrm{~s}$ duration in a lead with a normal resting tracing (five patients). In the 10 patients undergoing coronary arteriography, four had significant narrowing of three major coronary arteries, three had involvement of two vessels, and three had single vessel disease. One patient had previous coronary artery bypass grafting with the angiographic demonstration of graft closure in one of three grafts and an abnormal exercise tolerance test. Twelve patients developed chest pain and ST segment depression during the baseline study while three had non-diagnostic tests. During propranolol treatment nine patients continued to manifest chest pain and ST segment changes, the remaining patients having non-diagnostic electrocardiographic changes. Seven patients had previous well documented myocardial infarctions. None of the patients had evidence of mitral valve prolapse. Three patients had earlier clinical evidence of congestive heart failure and were being treated with digitalis and/or diuretics during the study period. None of these patients had evidence of congestive heart failure, eithe: clinical or radiological, at the time of the study. In the three patients taking digoxin, the presence of coronary artery disease was documented by arteriography.

\section{EXERCISE TEST PROCEDURE}

Exercise testing was conducted in the supine position with a bicycle ergometer (Engineering Dynamics Corporation-Lowell, Mass.) during continuous electrocardiographic monitoring with an orthogonal lead system. Graded exercise was performed for four minutes at each work load beginning at $150 \mathrm{kpm}$ (kilopond metres) and continuing in increments of $150 \mathrm{kpm}$ until one of the following end-points was reached: (1) patient fatigue, (2) typical anginal chest pain, (3) an abnormal electrocardiographic response, or (4) significant ventricular arrhythmias. All tests were performed in the fasting state. Repeat exercise tests after the institution of oral propranolol were performed approximately three to four hours after a dose of propranolol and only after a minimum of three days at a stable dosage schedule. In all but one patient an equivalent or greater workload was achieved on propranolol (Table 1).

\section{DRUG ADMINISTRATION PROCEDURE}

After the baseline studies, oral propranolol treatment was instituted at 40 to $80 \mathrm{mg} /$ day administered as four equal doses every six hours. Dosages were increased in a stepwise fashion until the clinician caring for the patient believed the patient was receiving the maximal dose that was advisable. The mean propranolol dosage was $161 \mathrm{mg} /$ day (range $60 \mathrm{mg}$ to $400 \mathrm{mg}$ ) (Table 1). No patient had ischaemic chest pain or had taken glyceryl trinitrate during the four hours before the exercise studies and none showed an important change in clinical 
symptoms or physical examination between the two exercise studies.

\section{RADIONUCLIDE TECHNIQUES AND}

IMAGING PROCEDURE

Multigated equilibrium blood pool imaging was performed using in vivo labelling of red blood cells with unlabelled stannous pyrophosphate (New England Nuclear-Pyrolite) before $30 \mathrm{mCi}$ of $99 \mathrm{~m} T \mathrm{c}$ as sodium pertechnetate. ${ }^{11} 12$ Collection of data was performed with a standard gamma scintillation camera (Ohio Nuclear Series 100) equipped with an all purpose parallel hole collimator and interfaced with a dedicated on-lire computer system (Ohio Nuclear VIP-450). Resting equilibrium gated blood pool scintigrams were obtained in multiple projections including a $35^{\circ}$ LAO projection modified to include a $15^{\circ}$ caudad angulation of the collimator surface. Though this projection frequently separates the right from left ventricle, the angle of obliquity was always adjusted to allow the clearest separation between the ventricles while minimising the interventricular septal thickness. Resting studies were acquired for: (1) a preselected time interval (five to eight $\mathrm{min}$ ), (2) 28 frames per cardiac cycle, and (3) 90 to 100 per cent of the cardiac cycle. This resulted in a minimum of 200000 counts per frame of the study.

Before beginning the exercise study, the legs of the patients were raised into the bicycle pedals and, after allowing two minutes for equilibration, an additional resting scintigram was obtained. This was done to assess the effect of leg elevation alone on the indices of left ventricular function. These and all subsequent exercise scintigrams were acquired for: (1) a preselected time interval of three minutes, (2) 24 frames per cardiac cycle, and (3) 90 to 100 per cent of the cardiac cycle. This resulted in a minimum of 100000 counts per frame of the study. Exercise imaging was performed at each work load, beginning at $150 \mathrm{kpm}$ and continuing until the termination of the test. The work levels achieved during the baseline study and after propranolol treatment are shown in Table 1. f.t the beginning of the first and each subsequent work load, the patient exercised for one minute before beginning the three minute imaging period. This allowed the heart rate to attain levels that were consistent enough to allow gating to proceed smoothly.

CALCULATION OF SCINTIGRAPHIC LEFT VENTRICULAR EJECTION FRACTION AND VOLUMES

Left ventricular ejection fractions were determined from the time activity curve of the left ventricle by constructing a region of interest over the left ventricle in the frames corresponding to enddiastole (ED) and end-systole (ES). The number of counts within the region of interest was used to calculate the left ventricular ejection fraction using the formula:

$$
\text { LVEF }=-\frac{\begin{array}{l}
\text { Background corrected ED counts- } \\
\text { background corrected ES counts }
\end{array}}{\text { background corrected ED counts }}
$$

This method has been shown to correlate welı with results obtained by contrast ventriculography. ${ }^{13}$

Left ventricular volumes were estimated by a non-geometric technique recently developed and validated in our laboratory. ${ }^{14-16}$ Further support for this technique comes from the independent work of Slutsky et al. ${ }^{17}$ In brief, the end-diastolic and end-systolic frames were isolated from the multiframe gated study and used for further processing. Correction for background activity was performed using a linear intcrpolated background subtraction technique which provided a highly reproducible and objective assessment of background activity. ${ }^{16} \mathrm{~A}$ region of interest was constructed over the left ventricle at end-diastole and end-systole, cautiously excluding left atrial activity and adhering to consistent criteria for the definition of the ventricular borders. Scintigraphic estimates of left ventricular volumes were calculated from the activity of the left ventricular region of interest normalised for heart rate, acquisition time per frame, and activity per millilitre of peripheral venous blood. The following cquation was used for the scintigraphic estimation of left ventricular volumes:

$$
\text { Volume }=\frac{\frac{\text { Background corrected LV counts }}{\% \text { cycle acquired }}}{\frac{\text { No. of frames gated }}{\text { Peripheral blood activity } \times \mathrm{e}^{-\lambda t}}}
$$

where $\mathrm{e}^{-\lambda \mathrm{t}}$ is the general equation for isotope decay $\left(\lambda=0.693\right.$ /isotope half-life) and $T_{\text {total }}$ is the total acquisition time of the study. Because of chest wall attenuation, the scintigraphic estimates of ventricular volumes are consistently smaller than the angiographic ones. Hence, a regression equation was determined (angiographic volume $=4.98 \times$ scintigraphic volume estimate +6.91 ), and the results of the volume determinations expressed in terms of the regressed angiographic volume estimate. Since the y-intercept of the regression equation is not zero, back calculation of the left ventricular ejection fraction from the scintigraphically determined volumes differs slightly from the count-derived ejection fractions that are reported. Using this method, we have found 
excellent correlations $(r=0.95)$ between scintigraphic and angiographic left ventricular volume measurements. ${ }^{16}$ Using these left ventricular volume measurements, stroke volume and cardiac output were also derived.

A subjective analysis of left ventricular segmental wall motion was also obtained. The left ventricle was divided into five segments, and each segment graded according to the following scale: $3=$ normokinesis, $2=$ mild hypokinesis, $1=$ severe hypokinesis, $\emptyset=$ akinesis, and $-1=$ dyskinesis. Further breakdown of this grading scheme was allowed, hence, a score of 1.5 would indicate left ventricular segmental wall motion between mild and severe hypokinesis.

\section{STATISTICAL ANALYSIS}

Data are expressed as the mean $\pm(\mathrm{SD})$. Comparisons between radionuclide studies in individuals were made by the paired $t$ test, and comparisons between groups were performed with an unpaired $t$ test. Values were considered statistically significant when a two tailed $t$ test identified $p$ values of less than 0.05 .

\section{Results}

Ten of the 15 patients treated with propranolol showed improvement in their exercise tolerance tests, as manifested by either less chest pain at equivalent work loads, less ST segment depression with exercise at equivalent work loads, and/or an increased exercise capacity before the onset of symptoms or ST segment changes. In this group, four patients were able to increase their work capacity by one work level while on propranolol treatment (Table 1). Four of the 15 patients experienced no improvement in exercise tolerance or chest pain while on propranolol, and one patient had slight deterioration in exercise capacity (less work performed) without clinical evidence of congestive heart failure. In addition, one patient developed intolerance to propranolol, manifest by excessive fatigue, which resolved after discontinuation of the drug. In the seven patients with previous infarction there was good agreement between the location of resting wall motion abnormalities and the site of previous infarction. Left ventricular functional indices before and after propranolol were compared at the highest cquivalent work level achieved during both examinations.

\section{HEART RATE AND DOUBLE PRODUCT}

Both resting and peak exercise heart rates were lower while on propranolol (Tables 2 and 3). Mean resting heart rates before and after propranolol were $79 \pm 10$ beats $/ \mathrm{min}$ and $65 \pm 10$ beats $/ \mathrm{min}$, respectively. Mean peak exercise heart rate was $113 \pm 15$ beats $/ \mathrm{min}$ before treatment and $97 \pm 12$ beats $/ \mathrm{min}$ after propranolol. Both differences were statistically significant $(p<0.01)$. The mean resting double product was lower after propranolol $\left(105 \pm 24 \times 10^{2}\right.$ vs $\left.81 \pm 15 \times 10^{2}\right)(p<0.01)$, as was the mean peak exercise double product $(185 \pm 62 \times$ $10^{2}$ vs $\left.148 \pm 30 \times 10^{2}\right) \quad(\mathrm{p}<0.02)$. Four patients showed no blunting of exercise heart rate response during propranolol; nevertheless, three of these

Table 2 Baseline exercise test. Responses of left ventricular volumes and left ventricular ejection fraction to exercise during the baseline (pretreatment) exercise tolerance test

\begin{tabular}{|c|c|c|c|c|c|c|c|c|c|c|c|c|c|c|}
\hline \multirow[t]{2}{*}{$\begin{array}{l}\text { Case } \\
\text { No. }\end{array}$} & \multicolumn{2}{|l|}{$\begin{array}{l}E D V I \\
\left(m l / m^{2}\right)\end{array}$} & \multicolumn{2}{|l|}{$\begin{array}{l}E S V I \\
\left(m l / m^{2}\right)\end{array}$} & \multicolumn{2}{|l|}{$\begin{array}{l}S V I \\
\left(m l / m^{2}\right)\end{array}$} & \multicolumn{2}{|c|}{$\begin{array}{l}C I \\
\left(l / \min \text { per } m^{2}\right)\end{array}$} & \multicolumn{2}{|l|}{$E F$} & \multicolumn{2}{|l|}{$H R$} & \multicolumn{2}{|l|}{$\begin{array}{l}D P \\
\times 10^{2}\end{array}$} \\
\hline & $R$ & $E x$ & $\boldsymbol{R}$ & $E x$ & $R$ & $E x$ & $R$ & $E x$ & $R$ & $E x$ & $R$ & $E x$ & $R$ & $E x$ \\
\hline 1 & 83 & 102 & 32 & 43 & 51 & 59 & $3 \cdot 8$ & 5.9 & 0.65 & 0.60 & 74 & 100 & 126 & 180 \\
\hline 2 & 38 & 47 & 7 & 13 & 31 & 34 & $2 \cdot 9$ & $4 \cdot 9$ & 0.80 & 0.73 & 93 & 147 & 155 & 353 \\
\hline 3 & 41 & 48 & 14 & 13 & 27 & 36 & 1.9 & $4 \cdot 5$ & 0.72 & 0.79 & 70 & 125 & 91 & 200 \\
\hline 4 & 95 & 98 & 48 & 36 & 57 & 61 & 3.0 & 6.0 & 0.52 & 0.65 & 62 & 98 & 67 & 118 \\
\hline 5 & 85 & 89 & 31 & 27 & 55 & 62 & $3 \cdot 7$ & 6.5 & 0.67 & 0.73 & 68 & 105 & 85 & 173 \\
\hline 6 & 137 & 132 & 102 & 107 & 35 & 25 & $3 \cdot 2$ & $2 \cdot 7$ & $0 \cdot 27$ & 0.20 & 91 & 114 & 82 & 114 \\
\hline 7 & 68 & 84 & 21 & 31 & 47 & 54 & $3 \cdot 7$ & $5 \cdot 2$ & 0.72 & 0.66 & 78 & 96 & 105 & 163 \\
\hline 8 & 59 & 87 & 21 & 33 & 39 & 44 & 2.9 & $6 \cdot 1$ & 0.69 & 0.64 & 63 & 112 & 82 & 190 \\
\hline 9 & 96 & 127 & 40 & 47 & 57 & 80 & $4 \cdot 1$ & 8.0 & 0.61 & 0.65 & 73 & 108 & 91 & 162 \\
\hline 10 & 54 & 55 & 27 & 25 & 28 & 30 & $2 \cdot 4$ & $3 \cdot 4$ & 0.55 & 0.58 & 90 & 114 & 113 & 182 \\
\hline 11 & 135 & 146 & 86 & 88 & 50 & 58 & 4.0 & $6 \cdot 2$ & 0.38 & 0.41 & 80 & 106 & 96 & 127 \\
\hline 12 & 47 & 56 & 11 & 11 & 36 & 44 & 3.0 & 4.9 & 0.83 & 0.85 & 84 & 110 & 118 & 154 \\
\hline 13 & 90 & 95 & 45 & 22 & 45 & 73 & $4 \cdot 0$ & $10 \cdot 3$ & 0.52 & 0.80 & 88 & 142 & 123 & 284 \\
\hline 14 & 91 & 111 & 61 & 74 & 31 & 37 & $2 \cdot 3$ & $3 \cdot 8$ & 0.35 & 0.34 & 74 & 105 & 89 & 168 \\
\hline 15 & 77 & 100 & 29 & 22 & 48 & 78 & $4 \cdot 3$ & $8 \cdot 6$ & 0.67 & 0.82 & 90 & 110 & 135 & 209 \\
\hline $\begin{array}{l}\text { Mean } \\
\text { SD }\end{array}$ & $\begin{array}{c}80 \\
+29 \cdot 2\end{array}$ & $\begin{aligned} & 92 \\
\pm & 29 \cdot 1\end{aligned}$ & $\begin{aligned} & 38 \\
\pm & 26 \cdot 2\end{aligned}$ & $\begin{array}{c}39 \\
+28 \cdot 4\end{array}$ & $\begin{aligned} & 42 \\
+ & 10 \cdot 6\end{aligned}$ & $\begin{aligned} & 52 \\
\pm & 17 \cdot 6\end{aligned}$ & $\begin{aligned} & 3 \cdot 3 \\
\pm & 0.76\end{aligned}$ & $\begin{aligned} & 5 \cdot 8 \\
\pm & 2 \cdot 04\end{aligned}$ & $\begin{array}{r}0.60 \\
\pm 0.16\end{array}$ & $\begin{array}{r}0.63 \\
\pm 0.18\end{array}$ & $\begin{array}{r}79 \\
\pm 10\end{array}$ & $\begin{array}{r}113 \\
\pm 15\end{array}$ & $\begin{array}{r}105 \\
\pm 24\end{array}$ & $\begin{array}{r}185 \\
\pm 62\end{array}$ \\
\hline
\end{tabular}

$R$, resting; Ex, exercise; EDV, LV end-diastolic volume; ESV, LV end-systolic volume; SV, stroke volume; CI, cardiac index; EF, LV ejection fraction; HR, heart rate; DP, double product (systolic blood pressure $\times$ heart rate). 
Table 3 Propranolol exercise test. Responses of left ventricular volumes and left ventricular ejection fractions to exercise during propranolol treatment

\begin{tabular}{|c|c|c|c|c|c|c|c|c|c|c|c|c|c|c|}
\hline \multirow[t]{2}{*}{$\begin{array}{l}\text { Case } \\
\text { No. }\end{array}$} & \multicolumn{2}{|l|}{$\begin{array}{l}E D V I \\
\left(m l / m^{2}\right)\end{array}$} & \multicolumn{2}{|l|}{$\begin{array}{l}E S V I \\
\left(m l / m^{2}\right)\end{array}$} & \multicolumn{2}{|l|}{$\begin{array}{l}S V I \\
\left(m l / m^{2}\right)\end{array}$} & \multicolumn{2}{|c|}{$\begin{array}{l}C I \\
\left(l / \min \text { per } m^{2}\right)\end{array}$} & \multicolumn{2}{|l|}{$E F$} & \multicolumn{2}{|l|}{$H R$} & \multicolumn{2}{|l|}{$\begin{array}{l}D P \\
\times 10^{2}\end{array}$} \\
\hline & $R$ & $E x$ & $R$ & $E x$ & $R$ & $E x$ & $R$ & $E x$ & $R$ & $E x$ & $R$ & $E x$ & $R$ & $E x$ \\
\hline 1 & 55 & 95 & 23 & 37 & 32 & 58 & $1 \cdot 7$ & $4 \cdot 4$ & 0.63 & 0.63 & 53 & 76 & 69 & 196 \\
\hline 2 & 62 & 96 & 13 & 11 & 48 & 86 & $2 \cdot 6$ & $7 \cdot 1$ & 0.84 & 0.93 & 52 & 83 & 68 & 149 \\
\hline 3 & 49 & 53 & 12 & 14 & 37 & 39 & $2 \cdot 8$ & $4 \cdot 0$ & 0.82 & 0.79 & 76 & 102 & 95 & 168 \\
\hline 4 & 90 & 99 & 36 & 28 & 54 & 71 & 3.9 & $7 \cdot 1$ & 0.62 & 0.74 & 73 & 100 & 73 & 130 \\
\hline 6 & 154 & 200 & 121 & 147 & 33 & 52 & $2 \cdot 4$ & $5 \cdot 6$ & 0.22 & 0.27 & 74 & 106 & 70 & 127 \\
\hline 7 & 66 & 84 & 20 & 24 & 46 & 60 & $2 \cdot 4$ & $5 \cdot 1$ & 0.73 & 0.74 & 52 & 85 & 62 & 119 \\
\hline 8 & 48 & 61 & 16 & 17 & 32 & 44 & 1.8 & 3.9 & 0.71 & 0.66 & 56 & 88 & 78 & 136 \\
\hline 9 & 116 & 134 & 57 & 65 & 59 & 69 & 3.6 & $6 \cdot 6$ & 0.53 & 0.53 & 61 & 112 & 79 & 144 \\
\hline 10 & 85 & 84 & 47 & 44 & 38 & 40 & $2 \cdot 4$ & $3 \cdot 7$ & 0.47 & 0.50 & 64 & 93 & 83 & 139 \\
\hline 11 & 127 & 153 & 84 & 85 & 42 & 68 & $3 \cdot 5$ & $7 \cdot 1$ & 0.35 & 0.46 & 82 & 105 & 90 & 122 \\
\hline 12 & 69 & 66 & 16 & 15 & 53 & 50 & 3.6 & $4 \cdot 3$ & 0.82 & 0.81 & 68 & 85 & 122 & 144 \\
\hline 13 & 93 & 114 & 35 & 35 & 58 & 70 & $4 \cdot 2$ & $9 \cdot 4$ & 0.65 & 0.71 & 73 & 120 & 95 & 230 \\
\hline 14 & 96 & 103 & 57 & 63 & 39 & 41 & 3.0 & $4 \cdot 0$ & 0.43 & 0.41 & 76 & 98 & 95 & 147 \\
\hline $\begin{array}{l}\text { Mean } \\
\text { SD }\end{array}$ & $\begin{aligned} & 85 \\
&+29 \cdot 3\end{aligned}$ & $\begin{array}{l}101 \\
\pm 38 \cdot 4\end{array}$ & $\begin{aligned} & 39 \\
+ & 29 \cdot 1\end{aligned}$ & $\begin{aligned} & 42 \\
\pm & 35 \cdot 1\end{aligned}$ & $\begin{array}{c}46 \\
+10.5\end{array}$ & $\begin{aligned} & 59 \\
&+14 \cdot 6\end{aligned}$ & $\begin{array}{l}3 \cdot 0 \\
+0.75\end{array}$ & $\begin{aligned} & 5 \cdot 7 \\
\pm & 1 \cdot 68\end{aligned}$ & $\begin{array}{r}0.61 \\
\pm 0.18\end{array}$ & $\begin{array}{r}0.65 \\
\pm 0.18\end{array}$ & $\begin{array}{r}65 \\
\pm 10\end{array}$ & $\begin{array}{r}97 \\
\pm 12\end{array}$ & $\begin{array}{r}81 \\
\pm 15\end{array}$ & $\begin{array}{r}148 \\
\pm 30\end{array}$ \\
\hline
\end{tabular}

Abbreviations are the same as in Table 2.

four did show an improvement in left ventricular ejection fraction.

\section{END-DIASTOLIC AND END-SYSTOLIC VOLUMES}

Mean resting end-diastolic volume index did not change with propranolol $\left(80 \pm 29 \cdot 2 \mathrm{ml} / \mathrm{m}^{2}\right.$ before propranolol, $85 \pm 29 \cdot 3 \mathrm{ml} / \mathrm{m}^{2}$ after propranolol) (Fig. 1) (Tables 2 and 3). Similarly, peak exercise left ventricular end-diastolic volume index did not change significantly $\left(92 \pm 29 \cdot 1 \mathrm{ml} / \mathrm{m}^{2}\right.$ before propranolol, $101 \pm 38.4 \mathrm{ml} / \mathrm{m}^{2}$ after propranolol).

Left ventricular end-diastolic volume index, however, did increase significantly $(p<0.01)$ with exercise both before and after propranolol treatment. Before treatment, the mean rise with exercise was $17 \pm 13$ per cent, and after propranolol the mean rise with exercise was $20 \pm 20$ per cent. There was no correlation $(r<0.5)$ between the magnitude of reduction in resting heart rate and the degree of increase in resting left ventricular end-diastolic volume index with propranolol.

Mean resting left ventricular end-systolic volume index did not change before $\left(38 \pm 26.2 \mathrm{ml} / \mathrm{m}^{2}\right)$ or after $\left(39 \pm 29 \cdot 1 \mathrm{ml} / \mathrm{m}^{2}\right)$ propranolol (Fig. 2) (Tables 2 and 3). Similarly, mean peak exercise left ventricular end-systolic volume indices did not change during propranolol $\left(39 \pm 28.4 \mathrm{ml} / \mathrm{m}^{2}\right.$ before and $42 \pm 35 \cdot 1 \mathrm{ml} / \mathrm{m}^{2}$ during propranolol). In addition, there was no significant change in left ventricular end-systolic volume index with exercise either before or after propranolol.

STROKE VOLUME AND CARDIAC OUTPUT The mean resting stroke volume index before

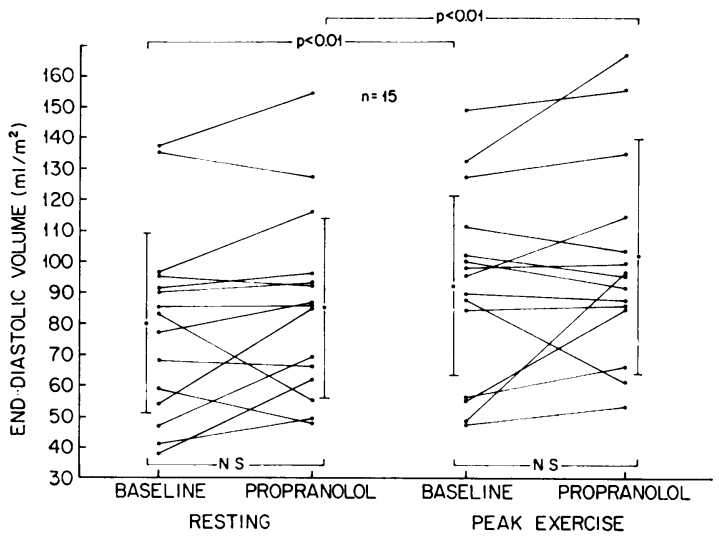

Fig. 1 The effects of propranolol on resting and peak-exercise end-diastolic volume is shown. The pretreatment study in this and subsequent figures is indicated as the baseline study. Mean values $( \pm S D$ ) are displayed to the side of the individual patient values. Though no significant changes were noted in left ventricular end-diastolic volume indices on propranolol treatment, conspicuous individual variation is shown.

propranolol was $42 \pm 10.6 \mathrm{ml} / \mathrm{m}^{2}$, whereas after propranolol it was $46 \pm 10.5 \mathrm{ml} / \mathrm{m}^{2}$ (NS) (Fig. 3) (Tables 2 and 3). Mean peak exercise stroke volume indices were similar before and during propranolol $\left(52 \pm 17.6 \mathrm{ml} / \mathrm{m}^{2}\right.$ before and $59 \pm 14.6 \mathrm{ml} / \mathrm{m}^{2}$ during propranolol) (NS). There was a significant increase in stroke volume index with exercise in both groups. Before propranolol, stroke volume index rose by $10 \pm 10.3 \mathrm{ml} / \mathrm{m}^{2}$ with exercise, 


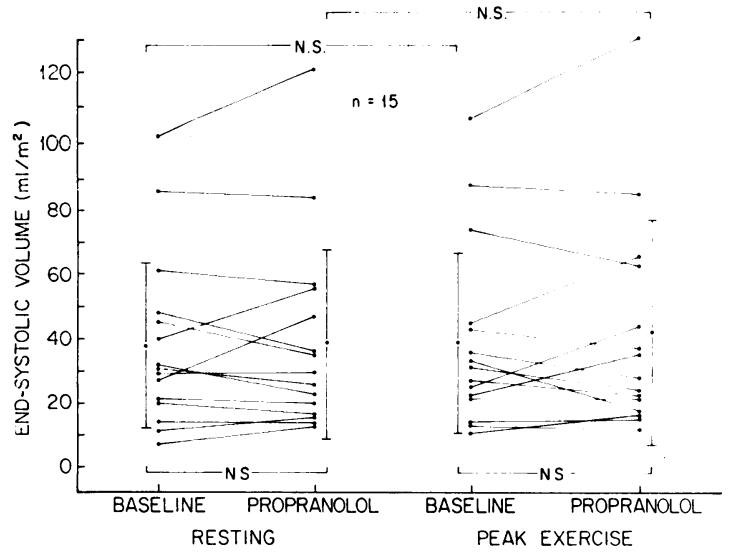

Fig. 2 Effect of propranolol on rest and exercise end-systolic volume. No substantial alterations in left ventricular end-systolic volume indices were seen before or after propranolol treatment. The format is identical to that in previous figures.

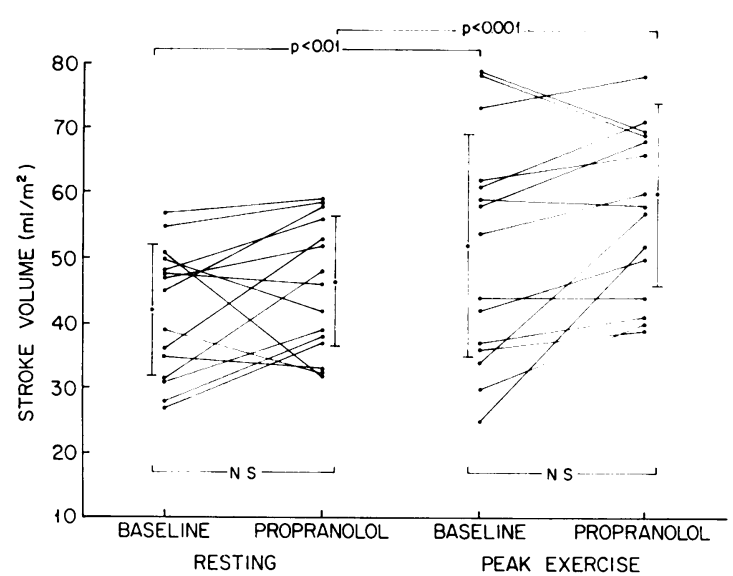

Fig. 3 Effect of propranolol on rest and exercise stroke volume. The format is as in previous figures. No consistent effect on stroke volume index was found.

whereas during propranolol treatment, stroke volume index rose by $14 \pm 11 \cdot 1 \mathrm{ml} / \mathrm{m}^{2}$ with exercise.

The mean resting cardiac index was not different before or after propranolol $\left(3.3 \pm 0.761 / \mathrm{min}\right.$ per $\mathrm{m}^{2}$ and $3.0 \pm 0.75 \mathrm{l} / \mathrm{min}$ per $\mathrm{m}^{2}$, respectively), nor was the cardiac index at peak exercise $(5 \cdot 8 \pm 2.04$ $1 / \mathrm{min}$ per $\mathrm{m}^{2}$ before and $5.7 \pm 1.681 / \mathrm{min}$ per $\mathrm{m}^{2}$ after the drug) (Fig. 4) (Tables 2 and 3). Cardiac index, however, rose significantly $(p<0.001)$ with exercise, and this rise was not altered by propranolol $\left(2.6 \pm 1.58 \mathrm{l} / \mathrm{min}\right.$ per $\mathrm{m}^{2}$ before and $2.7 \pm 1.31$ $1 /$ min per $\mathrm{m}^{2}$ after propranolol).

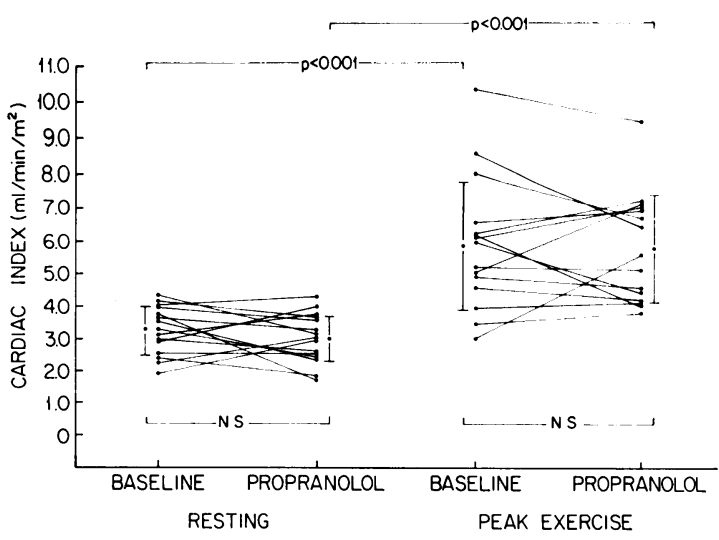

Fig. 4 Effect of propranolol on rest and exercise cardiac index. The format is as in previous figures. Though cardiac index increased with exercise in both groups, no effect of propranolol was seen.

\section{LEFT VENTRICULAR EJECTION FRACTION}

The mean resting left ventricular ejection fraction before propranolol was $0 \cdot 60 \pm 0 \cdot 16$, and after propranolol it was $0 \cdot 61 \pm 0 \cdot 18$ (NS) (Fig. 5). The mean peak exercise left ventricular ejection fraction was not different before or after propranolol treatment, $0.63 \pm 0.18$ vs $0.65 \pm 0.18$, respectively. Before propranolol treatment, there was no significant rise in mean left ventricular ejection fraction with exercise. After propranolol, however, mean left ventricular ejection fraction rose from $0 \cdot 61 \pm 0 \cdot 18$ to $0.65 \pm 0.18$ with exercise, a difference which, though small, was statistically significant $(p<0.05)$.

Data regarding interobserver, intraobserver, and individual patient variability suggest, however, that an absolute change in left ventricular ejection fraction of 0.05 or greater should be present to consider a change in left ventricular ejection fraction significant. ${ }^{17}$ Applying this criterion to the individual patient data, the response of the left ventricular ejection fraction to exercise before and after propranolol treatment can be recategorised (Fig. 6). Before propranolol, left ventricular ejection fraction increased with exercise in five of the 15 patients $(33 \%)$, was unchanged in five of the $15(33 \%)$, and deteriorated in five of the $15(33 \%)$. After propranolol, left ventricular ejection fraction improved with exercise in seven of the 15 patients $(47 \%)$, remained unchanged in seven of the $15(47 \%)$, and deteriorated in only one of the 15 patients $(6 \%)$ (Fig. 6). Fig. 6 also shows that five patients had an improved response in left ventricular ejection fraction from rest to exercise after propranolol, whereas in nine patients the left ventricular ejection fractions showed the same response to exercise before and after propranolol. The one patient 


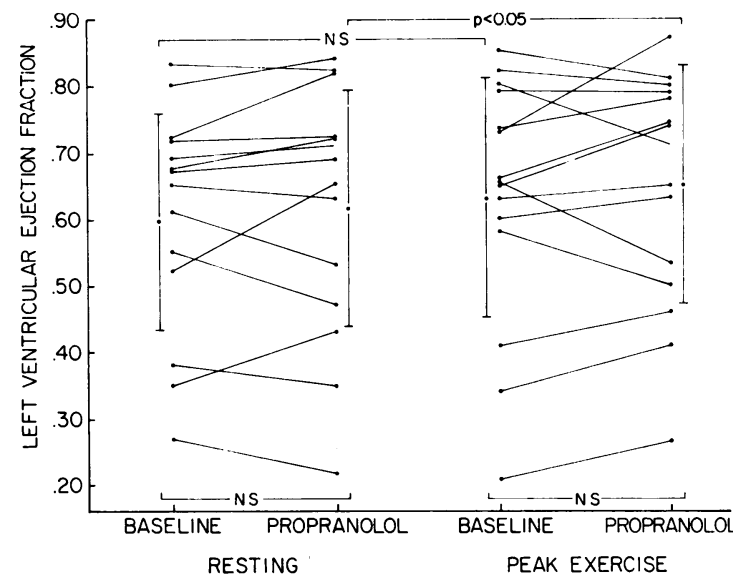

Fig. 5 Effect of propranolol on rest and exercise left ventricular ejection fraction. No significant change in resting ejection fraction was observed; however, after propranolol there was a small but statistically significant increase in left ventricular ejection fraction with exercise. Considerable individual variation in the magnitude and direction of the response of exercise left ventricular ejection fraction to propranolol is also shown.

(case 8) with a fall in exercise left ventricular ejection fraction before and after propranolol was subsequently shown to have severe $(>95 \%)$ stenosis of the left main coronary artery. The response of left ventricular ejection fraction to exercise in one patient (case 3) was worse during propranolol treatment when the comparison was made at the highest work level achieved before treatment (Tables 2 and 3). During propranolol treatment, however, this patient performed to the next highest work level, with a further increase in left ventricular ejection fraction to $0 \cdot 87$, allowing him to be recategorised into the improved response group. Thus, in most patients exercise left ventricular ejection fractions were either improved or unchanged by propranolol.

In order to assess further the improved exercise left ventricular ejection fractions after propranolol in five of the patients, the exercise induced changes in left ventricular volumes were compared with those in eight patients in whom exercise left ventricular ejection fractions were unchanged during propranolol (Table 4). The patient with left main coronary stenosis and the patient with a similar left ventricular ejection fraction response but at nonequivalent workloads were excluded from this analysis, since each may represent a special circumstance. Before propranolol, there was no difference in the mean change in left ventricular end-diastolic or end-systolic volume index with exercise between the two groups (Table 4). After propranolol, however, the mean change in left ventricular end-diastolic volume indices was larger in the

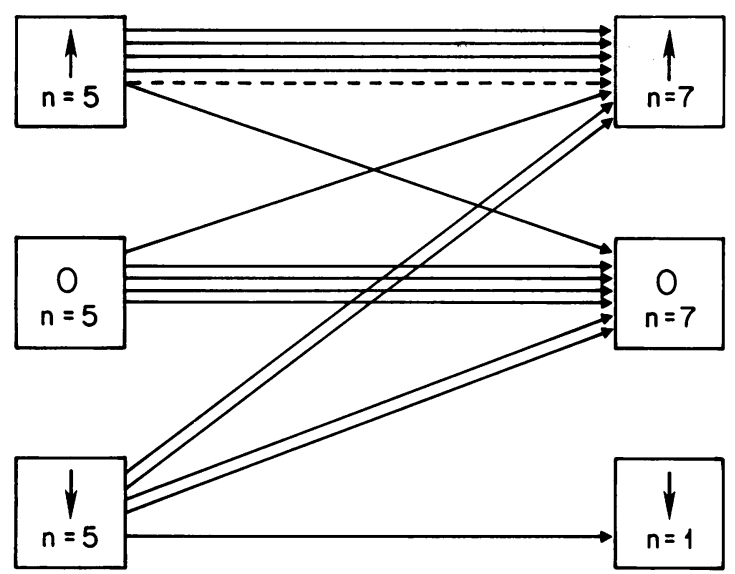

$\uparrow=$ IMPROVED EXERCISE LVEF $O=$ NO CHANGE IN EXERCISE LVEF $\downarrow=$ FALL IN EXERCISE LVEF
Fig. 6 Response of left ventricular ejection fraction to exercise before and after propranolol treatment. Each solid line represents the change in the response of exercise left ventricular ejection fraction during propranolol treatment in an individual patient. In five patients, the left ventricular ejection fractions during exercise were improved during propranolol treatment. One patient (case 3) had a poorer performance on propranolol (class $\uparrow$ to class 0 ) when the comparison was made at the highest work level achieved before propranolol. This same patient, however, exercised to a higher work level during propranolol treatment resulting in a further increase in left ventricular ejection fraction. This allowed the patient to be reclassified into a different response group (dashed line). 
Table 4 Exercise tolerance test. Changes in enddiastolic volume index and end-systolic volume index $(E D V I)(E S V I)$ during exercise in five patients with an improved left ventricular ejection fraction response on propranolol and in eight patients with the same left ventricular ejection fraction response during propranolol treatment

\begin{tabular}{lll}
\hline Patient Group & $\begin{array}{c}\text { Baseline } \\
\Delta E D V I \text { with exercise } \\
\mathrm{ml}^{2} \mathrm{~m}^{2}\end{array}$ & $\begin{array}{c}\text { Propranolol } \\
\Delta E D V I \text { with exercise } \\
\mathrm{ml} / \mathrm{m}^{2}\end{array}$ \\
\hline $\begin{array}{c}\text { Improved LVEF with } \\
\text { propranolol N =5 }\end{array}$ & $9 \pm 8.9$ & $33 \pm 11 \cdot 1 \quad(\mathrm{p}<0.001)$ \\
$\begin{array}{c}\text { Unchanged LVEF with } \\
\text { propranolol N = 8 }\end{array}$ & $6 \pm 11.5$ & $6 \pm 7 \cdot 1$ \\
& $\Delta E S V I$ with exercise & $\Delta E S V I$ witl exercise \\
\cline { 2 - 3 } $\begin{array}{c}\text { Improved LVEF with } \\
\text { propranolol N =5 }\end{array}$ & $7 \pm 3.7$ & $10 \pm 10 \cdot 4$ \\
$\begin{array}{c}\text { Unchanged LVEF with } \\
\text { propranolol N = 8 }\end{array}$ & $1 \pm 8.7$ & $-1 \pm 5.8$ \\
\hline
\end{tabular}

Abbreviations: Baseline, prepropranolol; $\triangle \mathrm{EDVI}$, change in LV end-diastolic volume index; $\triangle E S V I$, change in LV end-systolic volume index.

group with improved left ventricular ejection fractions compared with the patients with unchanged ejection fractions $\left(33 \pm 11 \cdot 1 \mathrm{ml} / \mathrm{m}^{2}\right.$ vs $6 \pm 7 \cdot 1 \mathrm{ml} / \mathrm{m}^{2}$, respectively; $\left.\mathrm{p}<0.001\right)$. It is unlikely that this was the result solely of alterations in heart rate, since the mean peak heart rates were equivalent in both groups $(91 \pm 13.6$ improved group vs $97 \pm 9.0$ unchanged group) [NS]). In addition, the magnitude of change in heart rate from rest to exercise, was similar. Similarly after propranolol, the mean change in left ventricular end-systolic volume indices with exercise was larger $\left(10 \pm 10.4 \mathrm{ml} / \mathrm{m}^{2} \mathrm{vs}-1 \pm 5.8 \mathrm{ml} / \mathrm{m}^{2}, \mathrm{p}<0.025\right)$ in the group with an improved exercise left ventricular ejection fraction response compared with those with unchanged left ventricular ejection fraction responses during exercise.

Four patients increased their exercise capacity after propranolol resulting in a further increase in double product. Two of these four reached the equivalent double product of the pretreatment exercise test, whereas in the remaining two, the double product remained diminished (Tables 2 and 3). Only one of these four (case 3) had a substantial increase in left ventricular ejection fraction with the increased workload.

\section{WALL MOTION ANALYSIS}

In the 15 patients, there was a total of 75 left ventricular wall segments available for evaluation (five segments/patient). The imaging projection used does not allow visualisation of all wall seg- ments, hence abnormalities in the anterior and inferoposterior regions will not be visualised directly. None the less, the development of abnormalities in these areas during exercise has the potential for effecting global left ventricular function and thus could be detected indirectly by alterations in left ventricular ejection fraction. In the seven patients with previous myocardial infarcts there was good agreement between the location of infarction and the location of resting wall motion abnormalities. Analysis of resting wall motion before propranolol indicated 18 of 75 segments $(24 \%)$ to be hypokinetic and six $(8 \%)$ to be akinetic. Seventy-nine per cent of these abnormal segments were in areas of previous infarction. After propranolol, 22 of 75 segments $(29 \%)$ were hypokinetic and seven of $75(9 \%)$ were akinetic. Overall, 14 of 75 segments $(18.6 \%)$ had less motion during propranolol, seven segments developing new mild changes ( $\leq 1$ unit) in areas that were previously normal and seven showing more severe changes in areas already abnormal. Ten of 75 segments (13.3) showed improved wall motion after propranolol.

Analysis of exercise left ventricular wall motion before propranolol showed 26 of 75 segments $(34.6 \%)$ to be hypokinetic and five of $75(6.7 \%)$ to be akinetic. After propranolol 23 of 75 segments $(30 \cdot 7 \%)$ were hypokinetic at exercise and eight of $75(10.7 \%)$ were akinetic. Overall, 13 segments $(17 \cdot 3 \%)$ were more hypokinetic on propranolol and $11(14 \cdot 7 \%)$ were less hypokinetic.

\section{Discussion}

Propranolol is currently the major beta-blocker used in the treatment of patients with angina pectoris. Since it is so frequently used, it is important that its effect on left ventricular function is characterised thoroughly both at rest and during exercise. This study was performed to assess the effect of oral propranolol on rest and exercise left ventricular end-diastolic and end-systolic volumes, stroke volume, cardiac output, and ejection fraction, all assessed during supine exercise with multigated equilibrium blood pool imaging. Recent developments with this radionuclide technique have shown it to be a reliable and reproducible method for the measurement of these indices of left ventricular function and segmental wall motion. ${ }^{13-22}$

In the patients studied, propranolol resulted in lower resting and exercise heart rates and double products. In addition, propranolol administration was associated with substantial improvement in exercise induced angina and/or work performance in most patients. These observations show that the 
study population received a substantial dose of propranolol.

Left ventricular ejection fraction is the most commonly used clinical index to assess global left ventricular function in patients. In the present study propranolol caused no change in resting global left ventricular ejection fractions, confirming the studies of Marshall et al. ${ }^{7}$ and Battler et al. ${ }^{8}$ who have reported similar results using radionuclide techniques. Previous studies using echocardiographic techniques have shown either no change $^{23}$ or a reduction ${ }^{6}$ in resting left ventricular ejection fraction with oral propranolol treatment. This discrepancy may, in part, be the result of the well recognised limitations of single dimension echocardiographic analysis in patients with segmental wall motion abnormalities. ${ }^{24}$ Though peak exercise left ventricular ejection fractions were not different on propranolol, there was a small (but significantly greater) increase in left vintricular ejection fractions from rest to exercise in the propranolol treated group. Further analysis of the individual patient responses to exercise before and after propranolol indicated no new deterioration in left ventricular ejection fractions with propranolol administration, even in the patients with resting ejection fractions less than 40 per cent before propranolol. Moreover, an increase in exercise left ventricular ejection fractions during propranolol was seen in one-third of the patients studied. Recent reports have indicated that oral propranolol causes substantial improvement in exercise left ventricular ejection fractions in patients with coronary artery disease. ${ }^{810}$ In a study of 10 patients with ischaemi cheart disease, Battler et al. ${ }^{8}$ concluded that the average left ventricular ejection fraction increased by 22 per cert relative to the value during the same exercise but without propranolol. Though our results indicate a statistically significant improvement in exercise left ventricular ejection fractions on propranolol, the increases were not as dramatic. In addition, our data suggest substantial individual variation in the exercise response of left ventricular ejection fraction to propranolol.

The scintigraphic estimation of left ventricular volumes in the patients studied helps to clarify the reason for at least part of this variation. Patients with an improvement in exercise left ventricular ejection fractions after propranolol had a significantly greater increase in left ventricular enddiastolic volume indices with exercise while on propranolol. In addition, in this subset of patients, there was a small but significant increase in left ventricular end-systolic volume indices with exercise during propranolol. These alterations in left ventricular volumes were not detectable in the subset of patients in whom similar changes in left ventricular ejection fractions occurred before and after propranolol treatment. Hence, improvement in left ventricular ejection fractions with propranolol appear to be associated with increases in left ventricular end-diastolic volumes during exercise. It is unlikely that these alterations in left ventricular end-diastolic volumes are secondary to alterations in heart rate alone, since both exercise heart rates and the change in heart rates with exercise were not significantly different in the two groups studied. The reason(s) for the alterations in left ventricular end-diastolic volumes is not clear, but it may have been related at least in part to altered left ventricular compliance.

Left ventricular end-systolic volume indices were not significantly changed during exercise or by propranolol in the study population as a whole; they, however, increased slightly during exercise in the subset of patients showing improvements in left ventricular ejection fractions after propranolol. Grossman et al. ${ }^{25}$ have shown that the contractile state of the left ventricle may be evaluated using endsystolic pressure-volume relations. If end-systolic volume serves as an index of contractility, it is not surprising that beta-blockade caused no change in resting end-systolic volume, since beta-adrenergic support of the left ventricle is small in the basal state. Previous investigations have shown a fall in left ventricular end-systolic volume during exercise in normal subjects. ${ }^{26-28}$ Our data obtained in patients with angina pectoris indicate that left ventricular end-systolic volume index does not change with exercise. This may be an additional manifestation of ischaemia and one indicating that contractility has been affected adversely. Sonnenblick et al. ${ }^{29}$ have shown that propranolol prevents an increase in contractility normally associated with exercise. This effect was possibly shown in the five patients who manifested an increase in exercise left ventricular end-systolic volumes after propranolol.

Three of the patients we studied had resting left ventricular ejection fractions of less than 40 per cent. During exercise, each of these patients showed a higher left ventricular ejection fraction while on propranolol, whereas at rest left ventricular ejection fractions were slightly lower in two of the three during propranolol treatment.

Resting and exercise left ventricular stroke volume indices were not different after propranolol; there was, however, prominent individual variability. This finding is in agreement with angiographic data obtained after the acute administration of intravenous propranolol. ${ }^{35}$ In the patients we studied, cardiac indices were not altered by pro- 
pranolol treatment at rest or during exercise. Exercise cardiac indices also disclosed a conspicuous degree of individual variation (Table 2, Fig. 3).

Subjective analysis of left ventricular wall motion also showed a heterogeneous response to propranolol treatment. Most left ventricular wall segments (approximately 68\%) remained unchanged during propranolol both at rest and during exercise. However, 18 per cent of the segments became more hypokinetic, whereas 14 per cent were less hypokinetic during propranolol. Previous reports of the effects of propranolol on left ventricular wall motion are conflicting. ${ }^{2} 452330$ Many of these previous investigations used intravenous propranolol; hence, the extrapolation of these data to those obtained with chronic oral treatment is unclear. While some previous studies have shown new or worsening areas of asynergy, ${ }^{5}$ others have failed to show any impairment in segmental left ventricular function. ${ }^{2}$ Non-invasive studies of the effect of chronic oral propranolol on left ventricular function are also conflicting. ${ }^{61}$ During experimental myocardial ischaemia, however, beta-adrenergic blockade has been shown to improve acutely regional left ventricular function, presumably by decreasing oxygen demand. ${ }^{32-34}$

In summary, the data obtained in the present study emphasise that the exercise response of left ventricular function to propranolol in patients with angina pectoris is complex and not entirely predictable. Propranolol resulted in either improved or unchanged left ventricular ejection fractions during exercise when compared with baseline responses, and notably did not result in a detrimental effect in patients with resting left ventricular ejection fractions less than 40 per cent. The mechanisms responsible for the increased left ventricular ejection fractions in a subset of patients are not clear but may be related in part to larger changes in left ventricular end-diastolic volumes during exercise. These functional alterations to propranolol, however, have been established during supine bicycle exercise and whether similar changes occur during upright exercise is unknown. Since the overall supine exercise left ventricular functional response to propranolol is heterogeneous, it may be advisable to obtain functional testing before and during exercise in selected patients to determine whether left ventricular function is beneficially altered. The radionuclide methods used in this study seem particularly well suited to allow such evaluation, since they permit rapid and relatively non-invasive measurement of left ventricular ejection fraction, left ventricular volumes, and presently at least a subjective analysis of left ventricular segmental wall motion.
The authors gratefully acknowledge the technical assistance of $\mathrm{Mr} \mathbf{R}$ Scott Lyons, $\mathrm{Mr}$ Norman Vance, and Mrs Jean Cruz in the performance of these studies. We also thank Drs Kenneth Narahara and Thomas Smitherman for the referral of a patient and acknowledge the support of the cardiac fellows, medical house officers, and nurses at Parkland Memorial Hospital whose help made this study possible.

\section{References}

1 Gianelly RE, Treister BL, Harrison DC. The effect of propranolol on exercise-induced ischemic S-T segment depression. Am $\mathcal{F}$ Cardiol 1971; 24: 161-5.

2 Shubrooks SJ Jr, Zir LM, Dinsmore RE, Harthorne JW. Left ventricular wall motion response to intravenous propranolol. Circulation 1975; 52: 124-9.

3 Wolfson S, Gorlin R. Cardiovascular pharmacology of propranolol in man. Circulation 1969; 40: 501-11.

4 Coltart DJ, Alderman EL, Robison SC, Harrison DC. Effect of propranolol on left ventricular function, segmental wall motion, and diastolic pressurevolume relation in man. $B r$ Heart $\mathcal{F}$ 1975; 37: 357-64.

5 Helfant RH, Herman MV, Gorlin R. Abnormalities of left ventricular contraction induced by beta adrenergic blockade. Circulation 1971; 43: 641-7.

6 Frishman W. Smithen C, Befler B, Kligfield P, Killip T. Noninvasive assessment of clinical response to oral propranolol therapy Am f Cardiol 1975; 35: 635-44.

7 Marshall RC, Berger HJ, Reduto LA, Cohen LS, Gottschalk A, Zaret BL. Assessment of cardiac performance with quatitative radionuclide angiocardiography. Effects of oral propranolol on global and regional left ventricular function in coronary artery disease. Circulation 1978; 51: 808-14.

8 Battler A, Ross J Jr, Slutsky R, Pfisterer $M$, Ashburn W, Froelicher V. Improvement of exerciseinduced left ventricular dysfunction with oral propranolol in patients with coronary heart disease. Am $\mathcal{F}$ Cardiol 1979; 44: 318-24.

9 Borer JS, Bacharach SL, Green MV, et al. Effects of propranolol on left ventricular function during exercise in patients with coronary artery disease (abstract). Circulation 1978; 57-58: Suppl. 11: 61.

10 Marshall R, Wisenberg G, Schelbert H, Rue C. Radionuclide evaluation of the effect of oral propranolol on left ventricular function during exercise in patients with coronary artery disease (abstract). Am $\mathcal{F}$ Cardiol 1979; 43: 398.

11 Stokely EM, Parkey RW, Bonte FJ, Graham KD, Stone MJ, Willerson, JT. Gated blood pool imaging following ${ }^{90 \mathrm{~m}} \mathrm{Tc}$ stannous pyrophosphate imaging. Radiology 1976; 120: 433-7.

12 Pulido JI, Doss J, Twieg D, et al. Submaximal exercise testing after acute myocardial infarction: myocardial scintigraphic and electrocardiographic observations. Am f Cardiol 1978; 42: 19-28.

13 Strauss HW, Zaret BL, Hurley PJ, Natarajan TK, 
Pitt B. A scintiphotographic method for measuring left ventricular ejection fraction in man without cardiac catheterization. Am $\mathcal{f}$ Cardiol 1971; 29: 57580.

14 Dehmer GJ, Lewis SE, Falkoff, $M$, et al. Determination of left ventricular volumes from time-activity data derived from equilibrium gated blood pool scintigraphy (abstract). Clin Res 1979; 27: 162A.

15 Dehmer GJ, Lewis SE, Hillis LD, et al. Nongeometric determination of left ventricular volumes from equilibrium blood pool scans. Am $\mathcal{f}$ Cardiol 1980: 45: 293-300.

16 Lewis SE, Dehmer GJ, Falkoff $M$, Hillis LD, Willerson JT. A nongeometric method for scintigraphic determination of left ventricular volume: contrast correlation (abstract). f Nucl Med 1979; 20: 661 .

17 Slutsky R, Karliner J, Ricci D, et al. Left ventricular volumes by gated equilibrium readionuclide angiography: a new method. Circulation 1979; 60: 556-64.

18 Wackers FJT, Berger HJ, Johnstone DE, et al. Multiple gated cardiac blood pool imaging for left ventricular ejection fraction: validation of the technique and assessment of variability. $A m$ f Cardiol 1979; 43: 1159-66.

19 Zaret BL, Strauss HW, Hurley PJ, Natarajan TK, Pitt B. A noninvasive scintiphotographic method for detecting regional ventricular dysfunction in man. $N$ Engl F Med 1971; 284: 1165-70.

20 Borer JS, Bacharach SL, Green MV, Kent $M$, Epstein SE, Johnston GS. Real-time radionuclide cineangiography in the noninvasive evaluation of global and regional left ventricular function at rest and during exercise in patient with coronary-artery disease. $N$ Engl f Med 1977; 296: 839-44.

21 Burow RD, Strauss HW, Singleton R, et al. Analysis of left ventricular function from multiplegated acquisition cardiac blood pool imaging. Comparison to contrast angiography. Circulation 1977; 56: 1024-8.

22 Pfisterer ME, Ricci DR, Schuler G, et al. Validity of left ventricular ejection fractions measured at rest and peak exercise by equilibrium radionuclide angiography using short acquisition times. $\mathcal{f} \mathrm{Nucl}$ Med 1979; 20: 484-90.

23 Parker JO, West RO, DiGiorgi S. Hemodynamic effects of propranolol in coronary heart disease. Am 7 Cardiol 1968; 21: 11-9.

24 Teichholz LE, Kreulen T, Herman MV, Gorlin R. Problems in echocardiographic volume determinations: echocardiographic-angiographic correlations in the presence or absence of asynergy. Am $\mathcal{f}$ Cardiol
1976; 37: 7-11.

25 Grossman W, Braunwald E, Mann T, McLaurin LP, Green LH. Contractile state of the left ventricle in man as evaluated from end-systolic pressurevolume relations. Circulation 1977; 56: 845-52.

26 Gorlin R, Cohen LS, Elliot WC, Klein MD, Lane FJ. Effect of supine exercise on left ventricular volume and oxygen consumption in man. Circulation 1965; 32: 361-71.

27 Sharma B, Goodwin JF, Raphael MJ, Steiner RE, Rainbow RG, Taylor SH. Left ventricular angiography on exercise. A new method of assessing left ventricular function in ischaemic heart disease. Br Heart F 1976; 38: 59-70.

28 Caldwell JH, Stewart DK, Dodge, HT, Frimer M, Kennedy JW. Left ventricular volume during maximal supine exercise: a study using metallic epicardial markers. Circulation 1978; 58: 732-8.

29 Sonnenblick EH, Braunwald E, Williams JF Jr, Glick G. Effects of exercise on myocardial forcevelocity relations in intact unanesthetized man: relative roles of changes in heart rate, sympathetic activity, and ventricular dimensions. $\mathcal{F}$ Clin Invest 1965; 44: 2051-62.

30 Wiener L, Dwyer EM Jr, Cox JW. Hemodynamic effects of nitroglycerin, propranolol, and their combination in coronary heart disease. Circulation 1969; 39: 623-32.

31 Pine M, Favrot L, Smith S, McDonald K, Chidsey CA. Correlation of plasma propranolol concentration with therapeutic response in patients with angina pectoris. Circulation 1975; 52: 886-93.

32 Maroko PR, Kjekshus JK, Sobel BE, et al. Factors influencing infarct size following experimental coronary artery occlusions. Circulation 1971; 43: 67-82.

33 Theroux P, Ross J Jr, Franklin D, Kemper WS, Sasayama S. Regional myocardial function in the conscious dog during acute coronary occlusion and responses to morphine, propranolol, nitroglycerin, and lidocaine. Circulation 1976; 53: 302-14.

34 Vatner SF, Baig H, Manders WT, Ochs H, Pagani M. Effects of propranolol on regional myocardial function, electrograms, and blood flow in conscious dogs with myocardial ischemia. 7 Clin Invest 1977; 60: $353-60$.

Requests for reprints to Dr Gregory J Dehmer, Ischaemic Heart Center; Room L5.134, University of Texas Health Science Center, 5323 Harry Hines Boulevard, Dallas, Texas 75235, USA. 